\title{
A proposed theoretical model of adult language learner autonomy
}

\author{
ÉVA ILLÉS* \\ Department of English Applied Linguistics, Eötvös Loránd University, Budapest, Hungary
}

(Received: December 15, 2018; accepted: February 14, 2019)

\begin{abstract}
This paper aims to answer how autonomy has been conceptualized in the literature, and what characterizes the different approaches to the conceptualization of adult English language learner autonomy in particular. The research identifies three perspectives on learner autonomy, which provides the theoretical framework for analysis. A summary of the conceptualization of each perspective is followed by examples of how a particular perspective has been implemented in language-teaching practice as well as the critical appraisal of the different perspectives, with special attention to adult learners. Apart from the comparison, another outcome of the investigation is a perspective of autonomy suitable for application in the 21st century context of adult English language learning and in preparation for the use of English as a global lingua franca.
\end{abstract}

Keywords: adult learner; perspectives on autonomy; English as a global lingua franca

\section{INTRODUCTION}

The somewhat cautiously put claim that "adult learners may learn language in a way that is different from the way children learn" (Lightbown \& Spada, 2006, p. 72) refers to one of the individual differences variables, that of age. In the literature, however, the difference between young(er) and older/adult learners is more clearly stated (e.g., among many others, Lightbown \& Spada, 2006; Kovács, 2011; Singleton \& Ryan, 2004; Smith \& Strong, 2009), and is based on the distinct characteristics of the two groups. Adult learners are seen as goal-oriented who often study to meet particular needs, such as meeting the demands of their jobs, moving up the career ladder, or exploiting emerging opportunities. "Adults are mature, competent, experienced, multitalented individuals who live complex lives and fulfil a variety of different life roles. They can draw on this wealth of previous life and educational experience for their learning, but they may learn in very different ways" (Smith \& Strong, 2009, p. 1). In addition, adult L2 learners are effective users of their mother tongue and represent a huge variety of individuals ranging from immigrants and refugees to international students and professionals. As a consequence, there are adult learners who are highly literate but there might also be ones who are illiterate or have literacy problems (Smith \& Strong, 2009), and may be learning English in a second-language environment or as a foreign language (Oxford, 2003).

Despite the above diversity, in this paper, adult L2 learners are treated as a separate group distinguished by age. Smith and Strong (2009) define young(er) language learners as those attending primary and secondary schools. Adopting this distinction, adult learners in this article are students in tertiary and adult education in both English as a second and foreign language contexts. Since the referenced literature and the issues raised in it are in English and concern English language teaching and learning, the focus of the paper is autonomy in relation to adult English language learners. The question the present research aims to answer is how autonomy has been conceptualized, and what characterizes adult English-language learner autonomy.

In the subsequent sections, first an overview of the definitions and perspectives on learner autonomy is provided in order to create a framework for analysis. It is followed by the critical appraisal of the different perspectives, with special attention to adult learners. Apart from a comparison, another outcome of the investigation is a perspective of autonomy suitable for application in the 21 st century context of adult English-language learning and in preparation for the use of English as a global lingua franca (ELF) (Seidlhofer, 2012).

\section{PERSPECTIVES ON LEARNER AUTONOMY}

There are many different ways autonomy can be perceived and represented (e.g., Benson, 2006). The three sets of perspectives adopted as a result of a brief overview in this section have been selected because they are concerned with the learner rather than the nature of autonomy itself and, directly or indirectly, they are relevant to adult learners. Some of the reasons for this are that they entail raising learners' awareness of goals, future needs, and aspirations as

\footnotetext{
* Correspondence: Éva Illés, Department of English Applied Linguistics, Eötvös Loránd University, Budapest, Hungary; Phone: +361485 5200/4383; Fax: +36 14604413 ; e-mail: illes.eva@btk. elte.hu
}

This is an open-access article distributed under the terms of the Creative Commons Attribution 4.0 International License, which permitsunrestricted use, distribution, and reproduction in any medium, provided the original author and source are credited, a link to the CC License is provided, and changes - if any - are indicated. (SID_1) 
well as the wider political context, all of which pertain to adult learners to a greater extent than to young ones.

Benson $(1997,2006)$ has suggested three ways of representing autonomy in language education. The technical perspective emphasizes the skills and strategies necessary for learners to be able to study on their own. The psychological perspective focuses on attitudes and abilities which make it possible for learners to take responsibility for their learning, while the political version of representing autonomy is concerned with the empowerment of learners in a wider, social context.

Oxford (2003) has expanded on Benson's tripartite model as well as modified the components where different perspectives should comprise. The technical perspective in this model constitutes the physical situation. The psychological perspective is broader than that of Benson's, and includes not only attitudes and abilities but also the "mental and emotional characteristics of learners, who are viewed either as individuals (...) or as members of a rather generalized social or cultural group (...)" (Oxford, 2003 , p. 83). The sociocultural perspective is concerned with "socially mediated learning" (Oxford, 2003, p. 83) and emphasizes the importance of interaction in learning. The political-critical perspective bears a close resemblance to Benson's political perspective in that it includes issues of power, ideology, and access in a learning context which is seen as highly political.

Littlewood's (1997) model distinguishes three types of autonomy that needs to be developed by teachers. In the context of the classroom, autonomy as a learner means developing learners' ability to take responsibility for their own learning and to use strategies which work for them individually. The second aspect is autonomy as a communicator, which entails learners becoming independent language users who can convey their own meanings in unpredictable real-life situations. The third kind of autonomy is autonomy as a person, which involves a wider context and the development of "greater generalized autonomy as individuals" (Littlewood, 1997, p. 82).

For a set of perspectives suitable for the exploration of various aspects of adult learner autonomy, the categories provided by Littlewood (1997) seem to serve as a good starting point in that Littlewood's categories, by and large, overlap with the components of Benson's and Oxford's models as well as highlight the different functions and roles adult learners fulfill. Autonomy as a learner thus covers Benson's (1997) technical and psychological perspectives and Oxford's (2003) psychological perspective. Autonomy as a communicator includes Oxford's (2003) sociocultural perspective which foregrounds interaction. Autonomy as a person can be interpreted as reference to the learner as a member of a community whose life and language learning are inevitably affected by the political context, including rights, responsibilities, and expectations in a given society. It, therefore, incorporates Benson's (1997) political and Oxford's (2003) politicalcritical perspective.

In the following, learner autonomy and adult learner autonomy, in particular, will be investigated and critically appraised in relation to the above three perspectives.

\section{AUTONOMY AS A LEARNER}

The basis for this most prevalent perspective is Holec's (1981) definition of autonomy as "the ability to take charge of one's learning" (p. 3), where learning refers to all aspects and stages of learning, from setting goals and determining content to selecting materials and assessment. This conception of autonomy, which is claimed to be "universally accepted" (Little, 2007, p. 14, 2009a, p. 223), originated in the context of the Council of Europe's endeavors to improve adult education in the 1970s. The idea was to make language learning more democratic by giving the learners the tools to define, guide, and control their learning process, so that learners can do things on their own and for themselves (Little, 2007). The ultimate objective of learner autonomy as independent, teacherless learning was realized in the form of self-access learning systems, which catered for adult learners who were unable to attend classroom-based courses in the early stages of the introduction of learner autonomy in education (Benson, 2006; Little, 2007).

The definition of autonomy as the learner's ability has been modified by Benson (2003), who suggests a broader notion than ability but, by and large, keeps the range of areas where autonomy should be practiced:

Autonomy is perhaps best described as a capacity ... because various kinds of abilities can be involved in control over learning. Researchers generally agree that the most important abilities are those that allow learners to plan their own learning activities, monitor their progress and evaluate their outcomes. (p. 290)

Since the aim of this perspective is to enable learners to reach a stage where they can study independently on their own, the development of autonomy can be seen as a transition from complete dependency to autonomy, the full control of the learning process (Nunan, 2003). Nunan (2003) suggests a nine-step program for the development of learner autonomy, beginning with making "instruction goals clear to learners" (p. 196) and allowing "learners to create their own goal" (p. 197) and ending with enabling learners to function as teachers and even researchers. Goal setting in relation to the desired end-product of language learning is of particular importance in this perspective of learner autonomy. It is partly based on "the belief that if lessons can be made more evidently relevant to outcomes and eventual use, they will be in turn more motivating" (Cook, 2007, p. 398), especially in the case of adult learners. The intermediate stages include encouraging students to decide what and how to learn as well as making choices and designing their own tasks.

Since developing the ability to be in control of one's own learning in formal instruction is necessarily " $a$ deliberate effort and conscious reflection" (Little, 2009a, p. 223), which requires the acquisition of metacognition and metalanguage that teachers possess, autonomous learners have to be trained, usually in the form of an add-on to language courses (Illés, 2012). Little (2007), who adopts a constructivist approach to learning, argues that learner training for 
the development of autonomy should be about involving learners "fully in planning, monitoring and evaluating their own learning" (Little, 2009a, p. 223).

Little (2009a, 2009b) emphasizes that the process should entail interaction between teachers and learners as well as between learners in the target language (TL). In this way, the improvement of L2 proficiency and the promotion of learner autonomy are carried out within the same process, which delimits but also defines autonomy as language learner autonomy. The reason for this interrelatedness is that "[in] the case of language learning, the interaction between language learning and language use means that the scope of a learner's autonomy depends in part on the extent of his or her target language proficiency" (Little, 2009b, p. 56).

\section{IMPLEMENTATION OF AUTONOMY AS A LEARNER IN ADULT EDUCATION}

The two prevalent modes of the implementation of autonomy as a learner are the European Language Portfolio (ELP) and Individual Learning Plans (ILPs), both of which have been extensively exploited in adult education. While ILPs have been used in the Teaching of English to Speakers of Other Languages (TESOL), ELPs are widespread in the teaching of English as a foreign language.

The ELP was developed to accompany the Common European Framework of References which assesses and defines levels of proficiency in the foreign language. Little (2009a, 2009b) claims that the ELP is suitable for developing learner autonomy: "beyond any reasonable doubt $[. .$. the ELP can foster language learner autonomy as I understand it, by supporting learners in goal setting, selfassessment and other form of reflection on language learning and language use" (Little, 2009a, p. 231). Little also argues (2007) that because the ELP-assisted development of autonomy has been tried and tested in several countries, this practice has universal currency, very much like Holec's seminal definition of autonomy.

Apart from the somewhat questionable claim that if something works in a particular context, it necessarily works everywhere else, Little (2009a) lists additional arguments in support of ELPs, including that one of the purposes for which the ELP has been developed was to make the learning process more transparent and promote learner autonomy. Thus, one of the three components of ELPs, the language passport, enables the learner to carry out and record the selfassessment of their proficiency of the TL. The language biography "supports goal setting and self-assessment in relation to specific learning objectives, and encourages reflection on learning styles, strategies and intercultural experience" (Little, 2009b, p. 62). The third component, the dossier, contains evidence of the learner's TL proficiency and may collect their work in progress. An additional benefit of the ELP is that it is in the TL and includes "can do" descriptors which, through individual self-assessment, allow the learner to have a detailed account of how far they have got in their learning of the TL.

One of the programs where the ELP was used is the Integrate Ireland Language and Training (IILT) scheme whose aim was to provide language courses for adult immigrants (Little, 2009a, 2009b). Since the intention was to "develop an institutional ELP culture" (Little, 2009a, p. 228), exploiting the ELP was compulsory for all the teachers. In his assessment of the use of ELP in IILT and quoting one teacher's positive feedback, Little (2009a) comes to the conclusion that the ELP can indeed foster learner autonomy "beyond any reasonable doubt" (p. 231).

A further example of the adoption of autonomy as a learner perspective is a self-directed learning course in an English for Academic Purposes program at a Japanese university (Murray, 2009). The aim was the development of language skills in tandem with metacognitive knowledge and metacognitive skills. The metacognitive domain reflected Holec's (1981) definition of autonomy in which it was concerned with planning, monitoring, and assessing the language-learning process of individual learners, which necessarily involved the transfer of "key elements of the pedagogy to students" (Murray, 2009, p. 62). Learning was personalized with the students making decisions about the content and pace of their learning. Authentic materials designed for native speakers of English, including movies, were suggested by teachers who acted as "facilitators and language advisers" (p. 63). In their feedback, the students pointed out that goal setting resulted in heightened motivation and they found it easier to communicate in the TL. Other benefits included improved reading speed and a better understanding of humor.

Another context in which autonomy as a learner perspective has been applied in adult education is the teaching English to Speakers to Other Languages in Britain and the United Sates, where the ILP has been introduced to be used by learners, staff, and also managers. The rationale behind the ILP, which can materialize in different ways (e.g., https://www.excellencegateway.org.uk/vocabulary/EGtheme/ Individual $\% 20$ learning\%20plans), is similar to that of the ELP. ILPs provide " $a$ personalized, flexible route map" (Learning and Skills Improvement Service, n.d.) to guide learners on their journey from setting learning goals, recording initial assessment information, and learning targets to indicating progress and achievements. When using ILPs, learners have to "negotiate and plan exactly what they are doing to do, how and when" (Learning and Skills Improvement Service, n.d.; emphasis in original). In Britain, ILPs are expected to include SMART targets, that is, they have to be "specific, measurable, achievable, relevant and time-bound" (Sunderland \& Wilkins, 2004, p. 8). ILPs also contain details, such as the success criteria to establish how success will be determined, information about the resources and the support learners will draw on as well as the place, and method used for learning the TL. Assessment in ILPs functions as a means of reflection and an opportunity to plan the next stages of the learning process. Given the second-language context of teaching English in Britain, the language used when working on the ILPs is necessarily English.

Another illustration of autonomy as a learner is the implementation of a participatory adult English as a Second Language (ESL) curriculum in an adult ESL class in the US (Lamping, 2009). The ILPs here included students' goals, activities chosen by the students and teachers as well as 
"self, peer, and teacher assessment" (Lamping, 2009, p. 75). They served as the basis of a process syllabus where the goals were continuously revised, leading to changes in other aspects of the learning process.

\section{APPRAISAL OF THE AUTONOMY AS A LEARNER PERSPECTIVE}

Even though Little (2009a) finds no fault with ELPs and claims that they are universally applicable, ELPs, ILPs, and the implied autonomy as a learner perspective have been subjected to criticism. One problem concerns the "can do" descriptors, which reflect language learning as a cumulative process of acquiring discrete units of language and skills. Sunderland and Wilkins (2004) argue that this runs counter to how language is acquired, and they question the linear development of language skills through the acquisition of measurable chunks. Their view is supported by LarsenFreeman (1997):

Learning linguistic items is not a linear process learners do not master one item and then move on to another. In fact, the learning curve for a single item is not linear either. The curve is filled with peaks and valleys, progress and backsliding. (p. 151)

In addition, the ELP descriptors in particular give learners the false sense of security that being able to perform a task in the classroom means being able to grapple with a similar challenge outside of the classroom in the future.

However, the "can do" descriptors seem only be part of the overall problem. Critics of ILPs in adult education in Britain, for instance, point out that setting measurable targets limits both learners and teachers in that targets that are not quantifiable have to be left out (Sunderland \& Wilkins, 2004). One such problematic area is language production, the level and quality of which often depends on the situation in which the TL is used. In addition, lower level learners, who, by definition, know little about the TL, have language problems, and also lack the knowledge that would enable them to identify areas of language knowledge and skills that need to be developed. This situation may be exacerbated by adult learners who are illiterate in their first languages. A further issue is that "it is very hard for language learners to analyze their own language performance" (Schellekens, 2004, p. 4), even when they are at a more advanced level.

The transfer of key elements of pedagogy (Murray, 2009) also presents a problem. Since the kind of metacognitive knowledge and skills required of autonomous learners entail pedagogic knowledge that traditionally teaching professionals possess, autonomy has to be developed as an add-on and in the form of learner training. In addition, learners who may know very little about the TL may find it difficult to identify their linguistic needs, the type of strategies that work for them as well as the materials which can provide the right comprehensible input (Krashen, 1982) in their particular circumstances. Callaghan (2004) argues that the time spent on the regular completion of ILPs is not only disproportionate to what can be gained from this exercise but also distorts the process of target setting and takes time away from other, perhaps more beneficial activities. Paradoxically, too, ELPs and ILPs strengthen the role of the teacher as the person whose guidance and assistance are essential for using these autonomy-enhancing methods and devices (Schellekens, 2004).

\section{AUTONOMY AS A COMMUNICATOR}

The conception of autonomy as a communicator aims to overcome the weaknesses of the view of autonomy as defined by Holec (1981). First of all, autonomy as a communicator perceives language learning and language use as inextricably interwoven, and bases the development of autonomy on a "use-in-order-to-learn" methodology (Grundy, 2007, p. 244). Since communication and language learning involve the same process, the development of learner autonomy is not an add-on, a supplementary course as in Murray (2009), but an integral part of language learning.

Therefore, the definition of autonomy as a communicator is as follows:

the capacity to become competent speakers of the target language who are able to exploit the linguistic and other resources at their disposal effectively and creatively. Autonomous learners are independent language users capable of online problem solving and decision making. (Illés, 2012, p. 509)

In autonomy as a communicator, both communication and learning are seen as complex, non-linear processes rather than as sets of predictable stages with foreseeable and quantifiable outcomes. Since each exchange in an interaction presents a different problem for the participants, learners cannot be given ready-made answers to previously defined problems. Rather, learners, if they want to become autonomous language users, have to be able not only to detect problems but also to solve them. Thus, a problemoriented approach develops autonomy as well as encourages learners to engage in lifelong learning. In addition, the perspective of autonomy as a communicator can prepare learners for communication in ELF contexts which, due to the linguistic and cultural variety of their users, are characterized by diversity, variability, and subsequent unpredictability (Seidlhofer, 2012).

In this perspective of autonomy, the kind of metacognitive knowledge and skills learners need to acquire comprise not pedagogical knowledge and skills but the type of knowledge and skills successful learner-communicators possess. According to Murray (2010, 2012), this implies raising learners' awareness of "pedagogical pragmatics" (2010, p. 294) whose main concern includes general principles that govern communication. In this respect, Murray (2012) suggests the application of two types of strategies: inductive and deductive. Inductive strategies enable learners to work out from examples how various speech acts are used and linguistically realized by both native and non-native 
speakers in English. Deductive strategies comprise the application of Grice's Cooperative Principle (1975), which provides a useful framework with its broad guidelines when making decisions about what counts as appropriate in a particular situation. Murray (2012) proposes a series of questions to encourage reflection. In line with Grice's Cooperative Principle, questions can be posed about the amount of information, the truthfulness and relevance of the message, and the use of politeness, as well as issues of clarity and the degree formality/informality.

It must be noted that although in this perspective language use takes precedence, not all aspects of the learning process are excluded, and control over learners' particular needs, such as researching a grammar problem or finding materials for a project, may remain within the learners' areas of decision-making (Illés, 2012).

\section{IMPLEMENTATION OF AUTONOMY AS A COMMUNICATOR}

Since learning through use is not age-specific, this perspective of learner autonomy can be promoted in all classrooms, albeit very differently, depending on the specifics of a particular learner or class. Therefore, methods which foster language learning in combination with language use can and should only offer general guidelines without much detail or practical advice. Given the fact that the perspective of autonomy as a communicator aims to develop learners' problem-solving capacity, the development of autonomy within this framework needs to provide conditions which, by engaging students in communication on their own terms, trigger problem-solving (Illés, 2012).

One of the ways of inducing problem solving is the teaching of literature. Since literature presents an alternative reality and often out-of-ordinary language use, resorting to conventional and customary meaning making does not suffice: "The writer of literature is really in the problemsetting business, and the reader of literature is in the problem-solving business par excellence. And because there is no right solution, such activities provide plenty of scope for discussion" (Widdowson, 1983, p. 32).

Another type of activity that engages learners in decision-making and problem-solving is translation, which is more than just replacing a word in one language with another one in a different language. Translation involves decision-making at all levels of language use, including the taking of a reciprocal perspective in order to establish what counts as relevant and effective for the target audience. Cook (2007) argues that "that translation in language learning might be useful cognitively, as an aid to language acquisition; pedagogically, as a motivating factor; and functionally, as a needed skill" (p. 398).

Computer-assisted language learning (CALL) projects, including the design of blogs or website, can also provide suitable conditions for the development of learner autonomy (Illés, 2012). Since these projects often come about as a result of team work, they enhance different types of classroom communication and foster interdependence (Little, 2009a). CALL projects are particularly suitable for students in secondary or higher education (see, e.g., Dias, 2009).

Another example of the practical application of autonomy as a communicator is an English for specific purposes course aiming to raise contextual awareness in healthcare workers (Bakó, 2014). Since patients may come from very different social, linguistic, or cultural backgrounds and the stakes of miscommunication are high, healthcare workers have to be acutely aware of the particular characteristics of the context in which they communicate. As a consequence, healthcare providers "must be prepared to function with higher levels of contextual awareness [...], as no protocol can be set for handling each and every situation" (Bakó, 2014, p. 135). Preparing healthcare professionals should, therefore, focus on the development of online problemsolving capacity, which will enable them to cope with the demands of undefined future eventualities and thus become autonomous LT users. In classroom practice, this entails reflection on the decisions made or to be made in a simulation of healthcare communication. The discussion of problems and solutions emerging during simulations not only broadens health science students' metaknowledge on how to communicate effectively in their particular context of use but also develops their problem-solving capacity through engaging them on their own terms.

Murray $(2010,2012)$ suggests a similar approach to the teaching and speaking of a foreign language in which he also aims to raise awareness of the choices that speakers make about what they say and how in particular contexts of use by discussing the circumstances that affect the making of choices. The questions designed to foster student reflection and with it autonomy as a communicator include, among others, the following (Murray, 2012):

\begin{abstract}
"During conversation, what do you think are some of the things that influence what we say and how we say it?" (p. 323) "Why are we sometimes indirect in the way we say things?" "Why might the amount we say be important?" (p. 324)
\end{abstract}

The discussion about the nature and different dimensions of communication develops learners' metaknowledge that they need in order to be able to use language not only correctly but appropriately as well.

\section{APPRAISAL OF AUTONOMY AS A COMMUNICATOR}

Even though this perspective is applicable in different teaching contexts regardless of the age of the learners, there are several reasons why the implementation proves challenging. One such problem is the lack of a suitable methodology which could provide guidance about the ways a problem-oriented approach could be applied in practice. Murray's (2010, 2012) or Bakó's (2014) examples show attempts of how it was done in their respective cases but in other teaching contexts it is the teacher of a particular classroom who has to make decisions about what and how to teach in order to develop their learners' problem-solving 
capacity. This then needs a rethinking of what methods and how should be used on the part of the teacher.

As can be seen from the examples above, the design of a methodology which suits a particular group of learners with different communicative needs, motives, and goals requires that teachers possess a sound knowledge of the theory of not only language learning but of language use as well. The knowledge of theory must be complemented by the teachers' capacity to activate and apply their knowledge to the solution of problems each new teaching context poses for them. However, this can only be achieved if teacher education involves more than offering ready-made solutions in the form of recipes and activities, and includes a sound understanding and critical appraisal of theory. In the practice of teaching, teachers should learn about their students as much as possible in order to be able to tailor the methods, materials, and techniques they use in accordance with the specific needs of their learners (Kálmán, 2018).

\section{AUTONOMY AS A PERSON}

This perspective aims to transcend the limitations of perspectives which locate learner autonomy within the individual learner, "independent of cultural, political, social or economic constraints" (Pennycook, 1997, p. 44). Autonomy as a person thus views learning, especially language learning, as a social activity (Schmenk, 2005) which takes place in a particular institutional context that is embedded in a wider social and cultural environment. The aim of language learner autonomy as a person is making learners active agents "in constructing the terms and conditions of their own learning" (Lantolf \& Pavlenko, 2001, p. 145), which includes controlling their learning and institutional context (Benson, 1997). Since this perspective contains issues of power, access, and ideology (Oxford, 2003), autonomy as a person applies mainly to adult learners, and results in increased "capacity for democratic engagement inside and outside the classroom" (Auerbach, 2008, p. 54). Autonomy in this sense thus implies not only being able to learn a language independently and efficiently, but also "critical reflectivity in the realm of language, language learning and beyond" (Schmenk, 2005, p. 110).

The inclusion of institutional and sociocultural contexts with their inherent diversity necessarily implies that autonomy cannot be seen as culturally neutral, which makes the claim that learner autonomy is universally appropriate untenable. This argument then brings the issue of autonomy as an ethnocentric concept into the fore. Indeed, autonomy has roots in the European Enlightenment and can be considered as a "Western construct, one that has strongly influenced modernist thinking about the subject and the emancipated individual in a democratic state" (Schmenk, 2005, p. 109).

Schmenk (2005) suggests that in order for autonomy to work in non-Western context, first it should be acknowledged that autonomy is a cultural construct. Autonomy then should be glocalized, that is, it should be adapted to its new environment through negotiating its meaning and potential benefits.

\section{IMPLEMENTATION OF AUTONOMY AS A PERSON}

In the examples below, the negotiation of autonomy takes place between native speaker teachers or native speaker contexts and adult learners.

Counseling sessions about the use and benefits of a selfaccess center at a Mexican university highlight the characteristics of the negotiation of the learning culture between native-speaker counselors and their Spanish-speaking students (Clemente, 2003). The pragmatic and conversational analysis of five sessions indicates that in the case of power relations, the counselors had inevitably the upper hand: it was the native-speaker counselors who usually controlled turn-taking and openings. Even though the conclusions of the article are positive and emphasize the benefits of guidance rather than imposition and control, three of the five learners included in the research expressed dissatisfaction regarding the outcome of their counseling sessions.

Another example of negotiation in the development of autonomy concerns the use of the learners' mother tongue in adult TESOL contexts. Auerbach (2008) suggests that rather than opting for an "English only" classroom, which may suit the monolingual native-speaker teacher but might create tension between teachers and students, the dilemma should be framed as a language learning issue with students being invited to take part in the decision-making. "This entails drawing out arguments, providing input, and addressing the pros and cons with learners" (Auerbach, 2008, p. 51). If the learners are proficient enough, the discussion may go beyond the classroom context and address questions about the political and ideological reasons for imposing English as the sole language of instruction in the TESOL context.

Another example of attempting to reconcile the Western perception of autonomy with cultures conceiving the notion differently is the stories of two Asian students in Benson, Chik, and Lim (2003). The students' narratives describe their journey that resulted in their "individual autonomy" (p. 24), which came about as a result of the students' response to the changing demands of the different contexts of learning and use of English (local and Anglo-Saxon in their case) as well as their inner negotiation of the meaning of a balanced approach that works for them. The development of individual autonomy was also helped by the students' motivation to learn English through which they also familiarized themselves with cultures initially foreign to them, including the Western perspective on autonomy.

\section{CRITIQUE OF AUTONOMY AS A PERSON}

The main criticism stems from the fact that this perspective of autonomy is a cultural construct representing an ethnocentric conception of the notion, namely, autonomy as an "idea originally developed in a Western cultural context" (Benson et al., 2003, p. 23). And there's the rub: The interpretation of culture along national or ethnic lines (Palfreyman, 2003), which leads to broad and unsubstantiated generalizations, such as the concepts of Western, 
Asian, or Japanese culture. Holliday (2003) calls this "reductive culturalism" (p. 110), which results in the polarity of "us" and "them," that is, juxtaposing those advocating the dominant "Western type" of autonomy on the one hand and learners who are expected to adopt it on the other.

Since "Western" in English-language learning refers to the English-speaking West (Holliday, 2003), "us" usually represents native speakers of the language. In English-language teaching, native speakers have been enjoying a special status in that they represent not only the target of learning English but are also the custodians of English-language teaching pedagogy. The rationale behind connecting language use and language teaching in such a way is that since real language is what is experienced by native speakers, those who have "privileged access" to it "are uniquely qualified to retail it as a product" (Widdowson, 2003, p. 157). This is what Holliday (2003) defines as native speakerism, which is "a set of beliefs supposing the view that "native speakers" represent the ideals both of the target language and of language teaching methodology" (p. 111).

However, this position by now has become untenable since in the 21st century the dominant use of English is its functioning as a global lingua franca where those who have been considered non-native speakers outnumber native speakers by a large margin. As a result, most non-native speakers use English in communication with other nonnative speakers (Graddol, 1997), and therefore non-native speakers shape and change the language the same way as their native speaker counterparts do (Newberry, Ahern, Clark, \& Plotkin, 2017; Seidlhofer, 2011).

\section{CONCLUSIONS}

The theoretical framework, which has provided the basis for the analysis of the different perceptions of learner autonomy in this paper, consists of three perspectives, autonomy as a learner, as a communicator, and as a person. Although all of them apply to adult learners, it is autonomy as a learner and as a person which have their roots in adult language learning contexts and which assume an adult cognitive background in order to work successfully. On the other hand, it is autonomy as a communicator with its problem-oriented approach, which seems to prepare learners for the demands of 21 st century communication where English predominantly functions as a global lingua franca. Age in this perspective also matters, albeit more indirectly, in that autonomy as a communicator requires "to select language and design activities which are locally appropriate to particular groups of learners" (Widdowson, 2003, p. 124). Autonomy as a communicator also has an advantage over autonomy as a learner as the former is not an add-on to language learning and its effectiveness does not depend on the learner's level of proficiency.

In order for an up-to-date model of adult learner autonomy, the individualized approach taken by the autonomy as a communicator perspective could be combined with the motivational force of goal-setting from autonomy as a learner and individual autonomy from autonomy as a person perspective as the target. Individual autonomy in this sense should be the adaption, rather than adoption, of various conceptions of autonomy in a way which suits a particular learner at a particular stage of their language-learning process. Then, this then necessarily implies lifelong learning and a dynamic and individual model of adult learner autonomy.

Funding sources: No funding has been received for this study.

Author's contribution: The author takes responsibility for the integrity and accuracy of the study.

Conflict of interest: The author declares no conflict of interest.

\section{REFERENCES}

Auerbach, E. (2008). Autonomy and democracy in language education. Language Issues, 19(1), 50-57.

Bakó, A. V. (2014). Capacity to handle complexity: The importance of contextual awareness in healthcare communication in English as a lingua franca. Economica, 7(4), 131-141.

Benson, P. (1997). The philosophy and politics of learner autonomy. In P. Benson \& P. Voller (Eds.), Autonomy and independence in language learning (pp. 18-34). London, UK: Longman.

Benson, P. (2003). Learner autonomy in the classroom. In D. Nunan (Ed.), Practical English language teaching. New York, NY: McGraw Hill.

Benson, P. (2006). Autonomy in language teaching and learning. Language Teaching, 40(1), 21-40. doi:10.1017/S0261444 806003958

Benson, P., Chik, A., \& Lim, H.-Y. (2003). Becoming autonomous in an Asian context: Autonomy as a sociocultural process. In D. Palfreyman \& R. C. Smith (Eds.), Learner autonomy across cultures: Language education perspectives (pp. 23-40). Basingstoke, UK: Palgrave Macmillan.

Callaghan, J. (2004). Diversity, ILPs, and the art of the possible. Reflect, 1, 6-7.

Clemente, M. A. (2003). Learning cultures and counselling: Teacher/learner interaction within a self-directed scheme. In D. Palfreyman \& R. C. Smith (Eds.), Learner autonomy across cultures: Language education perspectives (pp. 201-219). Basingstoke, UK: Palgrave Macmillan.

Cook, G. (2007). A thing of the future: Translation in language learning. International Journal of Applied Linguistics, 17(3), 396-401. doi:10.1111/j.1473-4192.2007.00160.x

Dias, J. V. (2009). A web of controversy: Critical thinking online. In A. F. V. Smith \& G. Strong (Eds.), Adult language learners: Context and innovation (pp. 97-105). Annapolis Junction, MD: TESOL International Association.

Graddol, D. (1997). The future of English? London, UK: The British Council.

Grice, P. (1975). Logic and conversation. In P. Cole \& J. Morgan (Eds.), Syntax and semantics 3: Speech acts (pp. 41-58). New York, NY: Academic Press.

Grundy,P.(2007). Language evolution, pragmatic inference, and the use of English as a lingua franca. In I. Kecskés \& L. R. Horn (Eds.), Explorations in pragmatics: Linguistic, cognitive and intercultural aspects (pp. 219-256). Berlin, GE: Walter de Gruyter. 
Holec, H. (1981). Autonomy in foreign language learning. Oxford, UK: Pergamon. (first published in 1979, Strasbourg: Council of Europe)

Holliday, A. (2003). Social autonomy: Addressing the dangers of culturalism in TESOL. In D. Palfreyman \& R. C. Smith (Eds.), Learner autonomy across cultures: Language education perspectives (pp. 110-126). Basingstoke, UK: Palgrave Macmillan.

Illés, É. (2012). Learner autonomy revisited. ELT Journal, 66(4), 505-513. doi:10.1093/elt/ccs044

Kálmán, Cs. (2018). EFL teachers' motivation and motivational impact in corporate context. Journal of Adult Learning and Innovation, 2(1), 33-47. doi:10.1556/2059.02.2018.03

Kovács, Á. (2011). The role of social environment in the formation of adult English language learners' attitudes to learning English: A pilot study. WoPaLP, 5, 100-117. Retrieved from http://langped.elte.hu/WoPaLParticles/W5Kovacs.pdf

Krashen, S. (1982). Principles and practice in second language acquisition. Oxford, UK: Pergamon.

Lamping, S. (2009). Stepping into a participatory adult ESL curriculum. In A. F. V. Smith \& G. Strong (Eds.), Adult language learners: Context and innovation (pp. 71-79). Annapolis Junction, MD: TESOL International Association.

Lantolf, J., \& Pavlenko, A. (2001). (S)econd (L)anguage (A)ctivity theory: Understanding second language learners as people. In M. Breen (Ed.), Learner contributions to language learning: New directions in research (pp. 141-158). London, UK: Longman.

Larsen-Freeman, D. (1997). Chaos/complexity science and second language acquisition. Applied Linguistics, 18(2), 141-165. Retrieved from https://www.uibk.ac.at/anglistik/staff/freeman/ course-documents/diane_chaos_paper.pdf

Learning and Skills Improvement Service. (n.d.). Introduction to this effective practice guide. Retrieved March 3, 2019, from https://www.google.co.uk/url?sa=t\&rct=j\&q=\&esrc=s\&source= web\&cd=1\&ved=2ahUKEwjBsIPLvPffAhUSGewKHci4BmQQ FjAAegQIBhAC\&url=https\%3A\%2F\%2Fapi.excellencegateway.org.uk\%2Fresource\%2Feg\%3A5377\&usg=AOvVaw 1BSOiyQEWfh8SWEYiP30_p

Lightbown, P. M., \& Spada, N. (2006). How languages are learned (3rd ed.). Oxford, UK: Oxford University Press.

Little, D. (2007). Language learner autonomy: Some fundamental considerations revisited. Innovation in Language Learning and Teaching, 1(1), 14-28. doi:10.2167/illt040.0

Little, D. (2009a). Language learner autonomy and the European Language Portfolio: Two L2 examples. Language Teaching, 42(2), 222-233. doi:10.1017/S0261444808005636

Little, D. (2009b). Learner autonomy in action: Adult immigrants learning English in Ireland. In F. Kjisik, P. Voller, N. Aoki, \& Y. Nakata (Eds.), Mapping the terrain of learner autonomy: Learning environments, learning communities and identities (pp. 51-85). Tampere, Finland: Tampere University Press.

Littlewood, W. (1997). Self-access: Why do we want it and what can it do? In P. Benson \& P. Voller (Eds.), Autonomy and independence in language learning (pp. 79-92). London, UK: Longman.

Murray, G. (2009). A self-directed learning course. In A. F. V. Smith \& G. Strong (Eds.), Adult language learners: Context and innovation (pp. 61-70). Annapolis Junction, MD: TESOL International Association.

Murray, N. (2010). Pragmatics, awareness raising, and the cooperative principle. ELT Journal, 64(3), 293-301. doi:10.1093/ elt/ccp056

Murray, N. (2012). English as a lingua franca and the development of pragmatic competence. ELT Journal, 66(3), 318-326. doi:10.1093/elt/ccs016

Newberry, M. G., Ahern, C. A., Clark, R., \& Plotkin, J. B. (2017). Detecting evolutionary forces in language change. Nature, 551, 223-226. doi:10.1038/nature24455

Nunan, D. (2003). Nine steps to learner autonomy. Retrieved from http://www.andrasprak.su.se/polopoly_fs/1.84007.1333707257!/ menu/standard/file/2003_11_Nunan_eng.pdf

Oxford, R. L. (2003). Toward a more systematic model of L2 learner autonomy. In D. Palfreyman \& R. C. Smith (Eds.), Learner autonomy across cultures: Language education perspectives (pp. 75-91). Basingstoke, UK: Palgrave Macmillan.

Palfreyman, D. (2003). Introduction: Culture and learner autonomy. In D. Palfreyman \& R. C. Smith (Eds.), Learner autonomy across cultures: Language education perspectives (pp. 1-19). Basingstoke, UK: Palgrave Macmillan.

Pennycook, A. (1997). Cultural alternatives and autonomy. In P. Benson \& P. Voller (Eds.), Autonomy and independence in language learning (pp. 35-53). London, UK: Longman.

Seidlhofer, D. (2011). Understanding English as a lingua franca. Oxford, UK: Oxford University Press.

Seidlhofer, B. (2012). The challenge of English as a lingua franca. Anglistik: International Journal of English Studies, 23(1), 73-86. Retrieved from https://angl.winter-verlag.de/ article/ANGL/2012/1/8

Schellekens, P. (2004). Individual learning plans: Fit for purpose? Reflect, 1, 4-5.

Schmenk, B. (2005). Globalizing learner autonomy. TESOL Quarterly, 39(1), 107-118. doi:10.2307/3588454

Singleton, D., \& Ryan, L. (2004). Language acquisition: The age factor (2nd ed.). Clevedon, UK: Multilingual Matters.

Smith, A. F. V., \& Strong, G. (2009). Adult language learners: An overview. In A. F. V. Smith \& G. Strong (Eds.), Adult language learners: Context and innovation (pp. 1-6). Annapolis Junction, MD: TESOL International Association.

Sunderland, H., \& Wilkins, M. (2004). ILPs in ESOL: Research and practice. Reflect, 1, 8-9.

Widdowson, H. G. (1983). Talking shop: Literature and ELT. ELT Journal, 37(1), 30-36. doi:10.1093/elt/37.1.30

Widdowson, H. G. (2003). Defining issues in English language teaching. Oxford, UK: Oxford University Press. 